\title{
Effect of Prosody of Rhythmic Yoga-Based Recitation on Positive and Negative Affect among Adolescents: A Four-Armed Comparative Study
}

\author{
Mollika Ganguly ${ }^{1}$, Sriloy Mohanty ${ }^{2}$, Sampadananda Mishra ${ }^{3}$, Sanjib Patra ${ }^{4} *$ \\ ${ }^{1} \mathrm{PhD}$. Scholar, SVYASA Yoga University, Bangalore, Karnataka, India \\ ${ }^{2} \mathrm{PhD}$ Scholar, Center for Integrative Medicine and Research, All India Institute of Medical Sciences, New Delhi, India \\ ${ }^{3}$ Director, Sri Aurobindo Foundation for Indian Culture (SAFIC), Pondicherry, India \\ ${ }^{4}$ Associate Professor, Department of Yoga, Central university of Rajasthan, Bandarsindri, Ajmer district, Rajasthan, India \\ *Corresponding author email: sanjib.patra@curaj.ac.in \\ https://doi.org/10.36018/dsiij.v17i.182
}

\begin{abstract}
Background: Adolescence is a critical period of maturation and immense emotional and behavioral changes. Yoga-based rhythmic recitations have been established to improve emotional personality features. Aim: The current four-arm comparative study attempted to appreciate the rhythmic recitations/prosody on Emotional personality among adolescents. Method: 138 adolescents (age $12.11 \pm 0.76$ years) satisfying inclusion and exclusion criteria were recruited and randomly allocated into four groups i.e., Humming the recitation following a Chanda(HR), Chanting a mantra (CM), Reading an English phrase, and Silent sitting, based on sections of their respective grades. Group intervention was done for 5 minutes, 3 times a day, for 30 days. According to their allocated group was provided. Subjects were assessed with positive and negative Affect Schedules (PANAS) at baseline and post-intervention. Result: There was no difference in both domains of PANAS in within group analysis. However, the positive affect was statistically significant when compared between the groups ( $>0.01$ ). A post-hoc analysis revealed the superiority of the CM and HM groups in positive affect alone when compared with other two groups. Conclusion: There was no statistical difference between CM and HM groups in both domains of PANAS. A humming prosody and mantra chanting demonstrated a similar effect on the amelioration of a positive Emotional personality among adolescents.
\end{abstract}

Keywords. Rhythmic recitation, Sanskrit Prosody, Positive and Negative Affect, Emotions, Adolescence, Psychology

\section{Introduction}

In Adolescence, a youngster experiences immense physical and social maturity along with the onset of puberty. There are drastic changes in cognitive

processes, psychological processes, and selfidentification, causing a sudden rise in stress levels (1-2). There has been an escalation of emotional and 
problems are conflicts with and between parents (3), conflicts at school, fear of rejection (4) leading to anger, anxiety (5), and antisocial behavior (6). Peerpressure caused by other factors plays a vital role in adolescent delinquencies (7). Higher levels of negative emotion reduce happiness and higher emotional variability, causing emotional disturbances leading to psychological and behavioral problems among adolescence (8). Thus, mindfulness practices are suggested to improve stability to reduce reactivity during stressful situations (9). Stress adversely affects positive thinking leading to several health and wellbeing outcomes. A study shows that simple maha-mantra chanting reduces both moderate and severe stress (10). Studies had shown the reduction of stress by chanting or mere listening to chants (11). Mantra chanting also enhances clarity of mind and helps elevate general cheerfulness (12). A significant impact of mantra chanting in improving performance IQ in children (13) and is suggested to be implemented in school for the overall development of a child (14). The Sanskrit prosodies meters are called Chandas. Rhythmic movements of breathing can affect neurophysiological functioning (15-16). In ancient texts, there are instances mentioned in the history of Indian poetry where the recitation of verses set in specific Chanda led to observable healing benefits. Based on the number, arrangements of syllables with pauses, and the number of syllabic instants in verse, Chandas are categorized. In classical Sanskrit poetry, there is a wide range of prosodies/Chandas. Among these Chandas, Totakam (17) is a popular Chanda with a simple pattern, hence compatible for children to follow. While there are studies on chanting and its effect, there is hardly any research done on the impact of Chandas specifically. The study aimed to evaluate the role of yoga-based recitation/Chandas on positive and negative emotions among school-going children. This study was designed to have four groups to nullify the effect of chanting a verse and language, to distinguish the impact of Chanda alone.

\section{Material and Methods}

Trial design

The current study was a four-armed parallel-group comparative trial, conducted in a CBSE school in Bangalore Urban, India. The subjects after recruitment were allocated into 4 groups. Humming the prosody i.e., Chanda without actual chanting (HC group), Chanting a mantra (CM group), reading an English phrase (EP group), and silently sitting (SS group) based on sections of their respective grades in school. The institutional ethical committee at SVYASA Yoga University, Bangalore, Karnataka, India approved the project and written consent was taken from the parents of all participants. The children gave verbal approval after explaining the detailed procedure of the research trial. The training and assessments were carried out during school hours. There was no stratification or blinding done in this study.

\section{Participants}

One hundred and forty students of 7th and 8th grade aged between 12 and 13 years (mean age 12.11 \pm 0.76 years) from a CBSE school in south India were approached. Information such as the demographic details, like children's health status and development and mother language was collected from the parents and school records. All the students were from middle or high economic backgrounds and were able to understand and write the English language. Children having any kind of learning disability, visual or verbal impairment were excluded from the study. Two students were excluded from the trial for 
having learning disabilities and were reported by their parents to the school authorities.

\section{Intervention}

The current research trial had four groups; 1) Humming the prosody or rhythmic recitation without actual chanting (HR group), 2) Chanting a Mantra (CM group), 3) reading an English phrase (EP group), and 4) silently sitting (SS group). The $\mathrm{HC}$ group was oriented into learning the rhythm (by humming) of a Yoga-based recitation called Totakam. Totakam is Yoga based recitation with a simple pattern and has 12 syllables where every third syllable is elongated. The reason for this intervention group was to nullify the effect of words or the meaning of the verse from chants completely. CM group children were made to learn a Sanskrit verse called Madhurashtakam, in Totakam Chanda, written by Shri Vallabhacharya. The EP group was taught an English phrase, "When your happiness is dependent upon what is happening outside of you, constantly you live as a slave to the external situation." by Jaggi Vasudev, widely known as Sadhguru and the Silent Sitting Group was requested to sit in silence observing their thoughts with their eyes closed. All the four groups were asked to practice their respective interventions for 5 minutes, 3 times a day, making it a 15 minutes intervention every day. Group-wise training was carried out in separate rooms, provided by the school. Every 10 students had one volunteer teacher to administer and report adherence to their practice. The CM and HR group were trained by the authors who are experts in Chandas and recitation of mantras. The phrasing, smoothness, and pace were closely monitored by the authors. Rhythm is an important part of chanting mantras which is our primary intervention.

\section{Outcome}

The Positive and Negative Affect Scale for Children (PANAS-C) was administered before and after the intervention. PANAS-C is a 27-item tool 18 to discern both the positive and negative affect of an individual and is among the most extensively used instruments to measure emotional and affect impairments. Positive affect implies experiencing feelings like happiness, joy, enthusiasm, alertness, etc. while Negative effect is related to experiencing feelings like anger, fear, guilt, etc. 19. PANAS is a highly reliable tool with its alpha reliability ranging from 0.86 to 0.90 for Positive effect and from 0.84 to 0.87 for Negative effect and when moderately intercorrelated $\mathrm{r}=-.2720$.

\section{Result}

All one hundred and thirty-eight subjects recruited completed the study (see Figure 1 for consort diagram). Table 1 represents the baseline characteristics of the subjects. At the time of recruitment, the one-way ANOVA demonstrated no significant difference between all four groups in their age and PANAS domains ( $p>0.05)$. No adverse events were reported as expected during the trial.

\section{PANAS}

The result across different groups is described in Table 2. The within-group analysis using sample t-test showed no significant changes in both positive and negative affect scores. However, there was a significant difference in positive affect scores $(p=0.01)$ between groups $(p=0.38)$. Later a posthoc analysis was carried out to appreciate the superiority, which revealed that the HR group had a distinct higher positive affect when compared to the EP reading and SS groups. There was no significant difference between HR and CM recitation without the verse. 


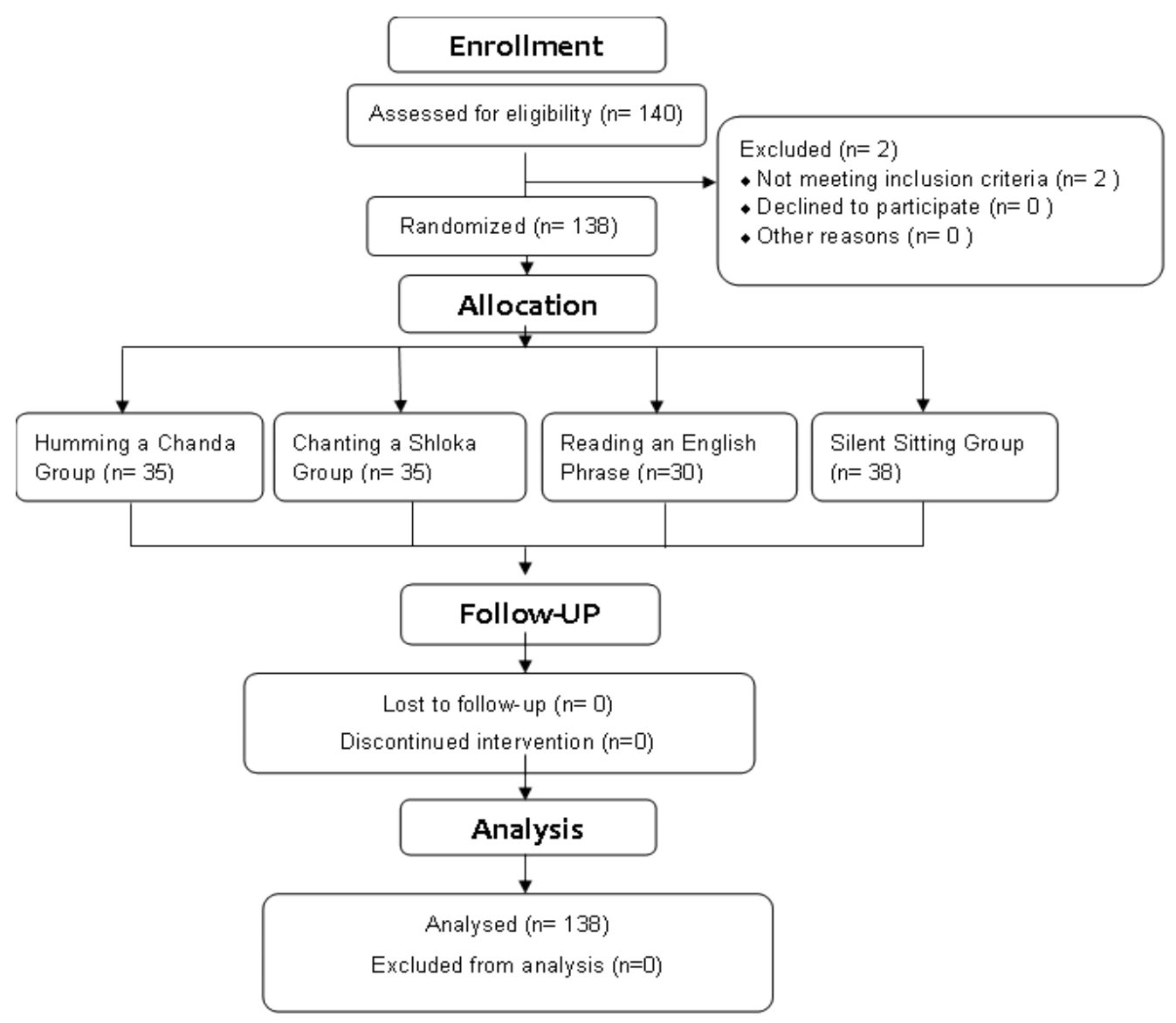

Figure 1. Flow chart of Study design

\begin{tabular}{|c|c|c|c|c|c|c|}
\hline & $\begin{array}{l}\text { Total } \\
(n=138)\end{array}$ & $\begin{array}{l}\text { Humming a } \\
\text { Chanda } \\
(n=35)\end{array}$ & $\begin{array}{l}\text { Chanting a } \\
\text { Shloka } \\
(n=35)\end{array}$ & $\begin{array}{l}\text { Reading an } \\
\text { English Phrase } \\
(n=30)\end{array}$ & $\begin{array}{l}\text { Silent Sitting } \\
(n=38)\end{array}$ & $\begin{array}{l}\mathrm{P}- \\
\text { value+ }\end{array}$ \\
\hline Age (years in mean $\pm S D$ ) & $12.11 \pm 0.76$ & $12.08 \pm 0.701$ & $12.17 \pm 0.706$ & $12.13 \pm 0.819$ & $12.05 \pm 0.803$ & \multirow{2}{*}{ NA } \\
\hline Gender - Female (\%) & $68(49.17 \%)$ & $14(40 \%)$ & $21(60 \%)$ & $18(60 \%)$ & $15(40.47 \%)$ & \\
\hline $\begin{array}{l}\text { PANAS Positive Affect } \\
(\text { mean } \pm S D)\end{array}$ & $45.57 \pm 9.65$ & $43.51 \pm 13.34$ & $48.65 \pm 5.35$ & $45.23 \pm 9.27$ & $44.89 \pm 8.60$ & $0.14+$ \\
\hline $\begin{array}{l}\text { PANAS Negative Affect } \\
(m e a n \pm S D)\end{array}$ & $34.33 \pm 11.89$ & $35.45 \pm 13.04$ & $31.80 \pm 9.60$ & $36.76 \pm 12.69$ & $33.71 \pm 11.97$ & $0.35+$ \\
\hline
\end{tabular}

Table 1. Baseline Characteristics of Subjects. PANAS- Positive and Negative Affect Scale. Notes: Data were presented as $n$ (\%) or mean standard deviation. +One way ANOVA was done to the PANAS-C components at baseline for normality. 


\begin{tabular}{|c|c|c|c|c|c|c|c|c|c|c|c|}
\hline Outcome & Stage & $\begin{array}{l}\text { Humming } \\
\text { (35) }\end{array}$ & $\begin{array}{c}\% \\
\text { change }\end{array}$ & $\begin{array}{l}\text { Chanting } \\
(n=35)\end{array}$ & $\begin{array}{c}\% \\
\text { change }\end{array}$ & $\begin{array}{l}\text { English } \\
\text { Phrase } \\
\text { Reading } \\
(n=30)\end{array}$ & $\begin{array}{c}\% \\
\text { change }\end{array}$ & $\begin{array}{l}\text { Silent Sitting } \\
\qquad(n=38)\end{array}$ & $\begin{array}{c}\% \\
\text { change }\end{array}$ & $p$-value & $\begin{array}{c}p \text {-value } \\
\text { (adjusted } \\
\text { for } \\
\text { baseline) }\end{array}$ \\
\hline \multirow{4}{*}{ POSITIVE } & Pre & $43.51 \pm 13.34$ & \multirow{4}{*}{$1.52 \%$} & $48.65 \pm 5.35$ & \multirow{4}{*}{$1.40 \%$} & $45.23 \pm 9.27$ & \multirow{4}{*}{$-6.00 \%$} & $44.89 \pm 8.60$ & \multirow{4}{*}{$-3.30 \%$} & 0.14 & \\
\hline & Post & $44.17 \pm 12.83$ & & $49.37 \pm 6.36$ & & $42.50 \pm 8.29$ & & $43.39 \pm 8.71$ & & $\underline{0.01}$ & $\underline{0.004 a, c}$ \\
\hline & MD & $-0.65 \pm 11.00$ & & $-0.71 \pm 4.23$ & & $2.73 \pm 9.65$ & & $1.50 \pm 8.10$ & & & \\
\hline & $p$-value & 0.72 & & 0.32 & & 0.13 & & 0.26 & & & \\
\hline \multirow{4}{*}{ NEGATIVE } & Pre & $35.45 \pm 13.04$ & \multirow{4}{*}{$-1.04 \%$} & $31.80 \pm 9.60$ & \multirow{4}{*}{$-0.72 \%$} & $36.76 \pm 12.69$ & \multirow{4}{*}{$-1.70 \%$} & $33.71 \pm 11.97$ & \multirow{4}{*}{$1.20 \%$} & 0.35 & \\
\hline & Post & $35.08 \pm 13.26$ & & $31.57 \pm 12.57$ & & $36.13 \pm 9.10$ & & $34.13 \pm 8.79$ & & 0.38 & 0.35 \\
\hline & MD & $0.37 \pm 14.57$ & & $0.22 \pm 10.00$ & & $0.63 \pm 12.57$ & & $-0.42 \pm 10.10$ & & & \\
\hline & $p$-value & 0.88 & & 0.89 & & 0.78 & & 0.79 & & & \\
\hline
\end{tabular}

Table 2. Changes during the study in the evaluated variable (Mean $\pm S D$ ) of the outcome and changes. Table demonstrates the one-way ANOVA between the groups at baseline and post treatment data. Baseline adjusted $p$ value is calculated for those parameters which were not normally distributed at baseline across the groups. $a=$ Chanting Vs English Phrase Reading, $b=$ Chanting Vs Humming, $c=$ Chanting Vs Silent Sitting, $d=$ English Phrase Reading Vs Humming, e = English Phrase Reading Vs Silent Sitting, $f=$ Humming Vs Silent Sitting

\section{Discussion}

As per the knowledge of the authors, the current study is the first attempt to explore the effect of prosody/Chandas i.e., the rhythm used to chant mantras. There are several studies on chanting suggesting they induce a psychotherapeutic effect (21), enhance mood and social cognition (22), memory (23) and improve performance IQ (13). The study recruited subjects in their early adolescence which is 11 to 13 years, it being a critical period of changes in behavior, moods, and relationships causing emotional turbulence (24). We had 4 parallel groups. (1) Humming the prosody without the verse, (2) Chanting a Mantra (prosody and verse), (3) reading an English phrase, and (4) silently sitting group to appreciate the effect of only Chanda/prosody without verse. The results of our study showed augmentation of Positive emotional personality in adolescence in both Chanda Humming (prosody alone, no verse) and Chanting a Mantra (prosody with verse) when compared to English phrase and silent sitting groups, which is in line with a study conducted by G. Perry et al., where positive affect increased more with vocal chanting than silent chanting (22). However, there was no statistical difference discerned between the humming and chanting groups, thus proving that it is the rhythm in which a mantra is chanted that has an impact on the spoken verse. Studies undoubtedly show chanting has a positive effect on brain activities (21) but Chanda is certainly a subtler way of impacting the mind by regulating feelings and enhancing positive emotions and may also alter the brain activity and autonomic variations as a long term effect, which is yet to be explored. Our results also conveyed that there was no statistical significance in the negative effect parameter of the PANAS scale. There were a couple of limitations to our study. It wasn't a randomized control trial as the school had four sections and did not allow us to shuffle children for randomization and intervention. No objective parameters like EEG or fMRI were taken. This study aimed at establishing the efficacy of the intervention as no preliminary study has been done before Chandas. The subjects were not 
stratified based on their gender, as females tend to face more negative affect than males, which can also be considered as a limitation to the study. Another study is underway considering existing limitations. There were no dropouts in the study which can be considered as strength. Secondly, a robust research method to explore the components of chanting by having four groups to eliminate the element of language, spoken verse, chanting of mantra and the Chanda/prosody alone was used in the study. Also, the study had adequate samples to show the improvement in the positive and negative affect in children and differentiation between the groups. More studies are warranted on Chandas with robust research methods, and objective tools like fMRI and EEG to further validate the results of the study. This will in turn augment our understanding of Chandas/Sanskrit Prosodies and also their potential to enhance mental wellbeing. We also hope that this study further encourages researchers to experiment with Chandas on children with special needs and behavioural disorders to have a tool to bridge their emotional and cognitive gaps which will be cost neutral as well as easy to incorporate.

\section{Conclusion}

The results of the current comparative study, though prelusive, support our hypothesis suggesting the mantra chanting and only humming the prosody without verse had a similar effect on emotional personality features of positive and negative affect. The results also suggest amelioration in the positive affect following chanting and humming the prosody, although there were no changes in the negative effect of PANAS across the groups.

\section{References}

1. Simmons RG, editor. Moving into adolescence: The impact of pubertal change and school context. Routledge; 2017 Jul 5. https://doi.org/10.4324/9781315124841

2. Blanco C, Wall MM, He JP, Krueger RF, Olfson M, Jin CJ, Burstein M, Merikangas KR. The space of common psychiatric disorders in adolescents: comorbidity structure and individual latent liabilities. Journal of the American Academy of Child \& Adolescent Psychiatry. 2015 Jan 1;54(1):45-52.

https://doi.org/10.1016/j.jaac.2014.10.007

3. Branje S. Development of parent-adolescent relationships: Conflict interactions as a mechanism of change. Child Development Perspectives. 2018 Sep;12(3):171-6.

https://doi.org/10.1111/cdep.12278

4. Lanthier R, Bates JE, Olson SL, Sandy JM. Early Developmental Precursors of Externalizing Behavior in Middle Childhood and Adolescence.

5. Kumar S. Management of Anger with Anger Reversal Technique among School Going Adolescents. International Journal of Psychology and Educational Studies. 2017;4(3):3241. https://doi.org/10.17220/ijpes.2017.03.004

6. Kobak R, Zajac K, Levine S. Cortisol and Anti-social Behavior in Early Adolescence: The Role of Gender in an Economically Disadvantaged Sample. Development and Psychopathology. 2009;21(2):579.

https://doi.org/10.1017/S0954579409000315

7. Defoe IN, Dubas JS, Van Aken MA. The relative roles of peer and parent predictors in minor adolescent delinquency: exploring gender and adolescent phase differences. Frontiers in public health. 2018 Sep 13;6:242.

https://doi.org/10.3389/fpubh.2018.00242

8. Beauchaine TP, Gatzke-Kopp L, Mead HK. Polyvagal theory and developmental psychopathology: Emotion dysregulation and conduct problems from preschool to adolescence. Biological psychology. 2007 Feb 1;74(2):174-84.

https://doi.org/10.1016/j.biopsycho.2005.08.008 
9. Ashe ML, Newman MG, Wilson SJ. Delay discounting and the use of mindful attention versus distraction in the treatment of drug addiction: a conceptual review. Journal of the experimental analysis of behavior. $2015 \mathrm{Jan}$;103(1):234-48.

https://doi.org/10.1002/jeab.122

10. Sekar L, Niva W, Maheshkumar K, Thangavel G, Manikandan A, Silambanan S, Shriraam V, Ramaswamy P. Effect of Mahamantra Chanting on Autonomic and Cognitive Functions-An Interventional Study. Journal of Clinical \& Diagnostic Research. 2019 May 1;13(5).

https://doi.org/10.7860/JCDR/2019/41236.12877

11. Kerdsurivong J, Rintra J, Wongsuphasawat K, Sittiprapaporn P. Stress reduction by Phochong chanting indexed by Thai Stress Test. Asian Journal of Medical Sciences. 2019 Aug 11;10(5):19-26.

https://doi.org/10.3126/ajms.v10i5.22461

12. Lolla A. Mantras Help the General Psychological WellBeing of College Students: A Pilot Study. Journal of religion and health. 2018 Feb 1;57(1):110-9.

https://doi.org/10.1007/s10943-017-0371-7

13. Chamoli D, Kumar R, Singh A, Kobrin N. The effect of mantra chanting on the performance IQ of children. Indian Journal of Positive Psychology. 2017 Sep 1;8(3):288-90.

14. Pradhan B, Derle SG. Comparison of effect of Gayatri Mantra and poem chanting on digit letter substitution task. Ancient science of life. 2012 Oct;32(2):89.

https://doi.org/10.4103/0257-7941.118540

15. Jovanov E. On physiological bases of states of expanded consciousness. InStates of Consciousness 2011 (pp. 203-221). Springer, Berlin, Heidelberg. https://doi.org/10.1007/978-3-642-18047-7_9

16. Kinabalu K. Immediate effect of 'nadishodhanapranayama'on some selected parameters of cardiovascular, pulmonary, and higher functions of brain. Thai journal of physiological sciences. 2005 Aug;18(2):10-6.
17. Mishra S. Handbook of Sanskrit prosody. Sri Aurobindo Society; 1999.

18. Laurent J, Catanzaro SJ, Joiner Jr TE, Rudolph KD, Potter KI, Lambert S, Osborne L, Gathright T. A measure of positive and negative affect for children: scale development and preliminary validation. Psychological assessment. 1999 Sep;11(3):326.

https://doi.org/10.1037/1040-3590.11.3.326

19. Ortuño-Sierra J, Bañuelos M, Pérez de Albéniz A, Molina BL, Fonseca-Pedrero E. The study of Positive and Negative Affect in children and adolescents: New advances in a Spanish version of the PANAS. PloS one. 2019 Aug 27;14(8):e0221696. https://doi.org/10.1371/journal.pone.0221696

20. Watson D, Clark LA, Tellegen A. Development and validation of brief measures of positive and negative affect: the PANAS scales. Journal of personality and social psychology. 1988 Jun;54(6):1063.

https://doi.org/10.1037/0022-3514.54.6.1063

21. Gao J, Fan J, Wu BW, Halkias GT, Chau M, Fung PC, Chang C, Zhang Z, Hung YS, Sik H. Repetitive religious chanting modulates the late-stage brain response to fear-and stress-provoking pictures. Frontiers in psychology. 2017 Jan 10;7:2055. https://doi.org/10.3389/fpsyg.2016.02055

22. Perry G, Polito V, Thompson WF. Chanting Meditation Improves Mood and Social Cohesion. InInternational Conference on Music Perception and Cognition (14th: 2016) 2016 Jul 5 (pp. 324-327). The Society for Music Perception and Cognition (SMPC).

23. Kalaivani MK. Assess the effects of Mrityunjaya mantra on memory and Visual and Auditory Reaction time of School students (Doctoral dissertation, Government Yoga and Naturopathy Medical College, Chennai).

24. Scott-Parker B, Watson B, King MJ, Hyde MK. The psychological distress of the young driver: a brief report. Injury Prevention. 2011 Aug 1;17(4):275-7. https://doi.org/10.1136/ip.2010.031328 